\title{
Reproducción social indígena, solidaridad económica y reciprocidad en la comunidad Qom de Pampa del Indio, Chaco
}

Indigenous social reproduction, economic solidarity and reciprocity in the Qom community of Pampa del Indio, Chaco

Julia Colla

Instituto de Humanidades y Ciencias Sociales del Litoral (IHUCSO Litoral)/CONICET, Argentina julialcolla@gmail.com

\section{Resumen:}

En este artículo analizamos las experiencias de producción agrícola y hortícola de los pueblos originarios Qom que conforman el movimiento social Federación Nacional Campesina (FNC) de la localidad de Pampa del Indio (provincia de Chaco). En un contexto de doble exclusión que impuso el desarrollo del capital en estos territorios, el objetivo es analizar la manera en que estas poblaciones se apropiaron de los programas de asistencia estatal e implementaron diversas estrategias para realizar prácticas campesinas que permitieron la reproducción social en sus territorios. Consideramos que el análisis de estas actividades permite comprender que el objetivo de estas comunidades es la reproducción social de la vida, la cual no se halla anclada a las nociones de rentabilidad, competencia en el mercado o acumulación de capital. El enfoque de abordaje es la etnografía y se han realizado entrevistas en profundidad a hombres y mujeres que integran la FNC y observación participante en diversas visitas a las chacras. Además, se utilizan fuentes secundarias para profundizar el análisis sobre las condiciones estructurales y de vida de estas poblaciones.

Palabras ClaVE: Reproducción social, Indígenas, Prácticas campesinas, Solidaridad económica.

\section{ABSTRACT:}

This article analyze the experiences of agricultural and horticultural production of Qom's indigenous people that take part on social movement "Federación Nacional Campesina" (FNC) in the town of Pampa del Indio (Chaco province). In a context of double exclusion, imposed by the capital develop in territories, the objective is to analyze the way in which families appropriated state assistance programs and activate their practical knowledge to carry out peasant practices. We consider that these productive projects allow us to understand that the objective of these communities is the social reproduction of life, and it is not related to the notions of cost effectiveness, market competition or capital accumulation. The methodology used is ethnography with participant observation and interviews carred out to men and women who are members of the FNC. In addition, secondary sources are used to go deep into the analysis of the structural and living conditions of these populations.

KEYWORDS: Social reproduction, Indigenous, Peasant practices, Economic solidarity.

\section{INTRODUCCIÓN}

En este artículo analizamos desde una perspectiva sociológica las experiencias de producción agrícola y hortícola de las familias pertenecientes a los pueblos originarios Qom que integran el movimiento social Federación Nacional Campesina (FNC). ${ }^{1}$ El objetivo es describir la manera en que estas poblaciones se apropiaron de los programas de asistencia estatal e implementaron diversas estrategias para realizar prácticas campesinas que permitieron la reproducción social en sus territorios. Nuestro trabajo se sitúa en la localidad chaqueña de Pampa del Indio y en particular entre aquellas familias que conforman dicho espacio político, el cual lleva adelante la autogestión de proyectos de producción agraria. ${ }^{2} \mathrm{Al}$ respecto, consideramos como hipótesis que estas poblaciones realizan prácticas campesinas para reafirmar su pertenencia comunitaria y fortalecer su etnicidad como pueblos indígenas Qom. ${ }^{3}$ 
Sucede que, en las últimas tres décadas, en la provincia de Chaco, la apertura de un nuevo ciclo de acumulación de capital y la crisis de la economía regional, vinculada con la producción del algodón, tuvo consecuencias directas sobre los territorios y las condiciones de vida de las poblaciones campesinas pertenecientes a la etnia Qom. ${ }^{4}$ La dinámica económica emergente planteó nuevas condiciones de exclusión que se sumaron a los procesos de subordinación social previos y generaron situaciones de indigencia, con altos índices de desnutrición y mortalidad entre las poblaciones más afectadas. Asimismo, los pueblos originarios tuvieron dificultades para desarrollar su vida comunitaria por la falta de acceso y control de los recursos naturales y sufriendo la vulnerabilidad en el cumplimiento de derechos específicos para dirimir conflictos territoriales. En consecuencia, durante el último decenio, sus prácticas de producción y reproducción social se tradujeron, en gran medida, en la utilización y apropiación de recursos económicos de asistencia para cubrir los gastos mínimos de sustento familiar y en el aprovechamiento de algunos insumos para la producción agraria y hortícola que brindaron distintos organismos estatales.

En Pampa del Indio, desde el año 2003 y de manera intermitente, los Estados nacional y provincial articularon demandas con los movimientos campesinos e indígenas de la zona para realizar programas de asistencia. En general, estos tenían como objetivo la canalización de recursos para el desarrollo de emprendimientos agrícolas y el fortalecimiento de marcos institucionales para el aumento del consumo interno (Merklen, 2005). En cada momento, quienes participaron de los mismos debieron cumplimentar requisitos formales establecidos por las instituciones estatales y, para ello, organizarse para autogestionar y distribuir los recursos: tramitar personería jurídica, conformar un organigrama de responsabilidades para la creación de una Asociación Civil, aprender a realizar tareas administrativas y contables, entre otros. Pero también la implementación en el territorio trascendió los objetivos propuestos y benefició el desarrollo de mecanismos alternativos y autónomos para la reproducción social de estas poblaciones. Estas nuevas dinámicas emergieron a partir de la voluntad de los Qom de trabajar en sus parcelas y de organizar la vida de otra manera en base a su identidad étnica.

En esta línea, las actividades que se llevaron a cabo estuvieron articuladas entre los requerimientos formales de los programas y el conocimiento práctico acumulado de experiencias pasadas y relacionados con una forma no instrumental de concebir el territorio, la naturaleza y el monte. ${ }^{5}$ Asimismo, esto se desarrolló bajo una organización interna comunitaria a partir de las familias extendidas dentro de cada parcela y paraje rural, con participación democrática -asambleas, cuerpos de delegados- para la toma de decisiones y con liderazgos indígenas surgidos de la acción colectiva.

En el caso de las experiencias de producción algodonera realizadas en el período 2003-2011, la posibilidad de comercialización planteó alternativas de autonomía económica, diferentes a la dependencia que tenían en el pasado reciente como trabajadores temporales en la carpida y cosecha. Mientras que en la producción agrícola y hortícola de autoconsumo llevadas a cabo desde 2016, se desarrollaron relaciones de intercambio para distribuir y compartir los alimentos entre las familias bajo el principio de reciprocidad, con una lógica diferente a la de rentabilidad, comercialización de excedentes y competencia en el mercado.

Podríamos decir que estas poblaciones indígenas se reapropiaron de manera práctica de los programas estatales, para imprimirles revisiones y modificaciones en base a sus formas de pensar, obrar y sentir propias de su identidad étnica y posición en la estructura social. Estas prácticas cotidianas -en tanto habitus (Bourdieu, 2007) - tuvieron como cuestión fundamental ampliar el campo de posibilidades para que tengan lugar otras opciones que habían sido marginalizadas e invisibilizadas por los procesos de sometimiento colonial (Santos, 2011). Por ejemplo, las diversas formas de relacionarse con la naturaleza, las relaciones de reciprocidad y solidaridad económica. Las mismas fueron reconfiguradas para organizar las actividades y emergieron como estrategias en el orden comunitario y con un planteamiento político explícito de transformación social.

La solidaridad económica, entendida como una forma de organización basada principalmente en unidades domésticas de trabajo familiar orientadas a resolver problemas de sobrevivencia, proporcionar beneficios comunitarios y satisfacer necesidades integrales colectivas, apeló a los lazos de solidaridad y a una racionalidad 
no capitalista como principales mecanismos articuladores (Marañón-Pimentel, 2012). En este sentido, los campesinos Qom buscaron como objetivo básico la reproducción de la vida para resolver su subsistencia unido al proyecto político de la FNC vinculado a visibilizar la importancia de la economía campesina para el desarrollo de las economías regionales.

En términos generales, este artículo pretende aportar un análisis sociológico sobre la manera en que el habitus permite reproducir las condiciones de su propia producción social (Bourdieu, 2014). Es decir, cómo el conocimiento práctico aprendido en las experiencias pasadas y actualizado en las prácticas campesinas se activa para la reproducción social de estas poblaciones indígenas. En efecto, estas estrategias individuales o colectivas, conscientes (encarnadas en reivindicaciones y propuestas étnicas) o inconscientes (reflejadas en actitudes, valores y pautas de conductas) surgen en gran medida durante las crisis del modo de reproducción. De hecho, se instalan como réplicas a las distintas expresiones de coerción a las que son sometidos por la sociedad hegemónica (Bigot, Rodríguez y Vázquez, 1992; Bourdieu, 2014). Esto nos permite poner en debate la existencia de relaciones sociales no capitalistas que pugnan en desigualdad de condiciones para sobrevivir en los territorios subsumidos formalmente por el capital. De aquí reside el fundamento de resistencia de un sujeto indígena que reivindica sus prácticas campesinas para recrearse en el territorio, con mayor capacidad de acción frente a la subordinación, y con mejores condiciones para vivir en el medio rural.

Esquemáticamente, este trabajo se encuentra organizado de la siguiente manera: en principio, se describen las transformaciones económicas estructurales sucedidas desde inicios de 1990 y su relación con las condiciones de doble exclusión social en las que se vieron inmersas las familias Qom. Luego, se identifican dos momentos en la historia reciente (2003-2011 y 2016-2018) de los pueblos originarios de Pampa del Indio donde se implementaron estrategias alternativas de producción agrícola y hortícola. En dichas etapas, separadas por un período extenso de sequía que afectó los cultivos y la salud de la población, se describen las experiencias de producción algodonera de las unidades familiares con destino a la comercialización (2003-2011) y las estrategias comunitarias para la producción de alimentos con fines de autoconsumo (2016-2018). En ellas, se analizan las prácticas de solidaridad económica que tuvieron las familias indígenas para la organización, autogestión de recursos, cultivo y comercialización de la producción. Finalmente, se reflexiona sobre las relaciones de intercambio basadas en el principio de reciprocidad - "repartir", "pedir" y "convidar"- y las acciones que habilitan y restringen estas prácticas distributivas.

\section{Metodología}

Este trabajo se enfoca en una muestra no aleatoria de los campesinos pertenecientes a la etnia Qom que integran alguna de las tres organizaciones más numerosas de la zona que conforman la Federación Nacional Campesina (FNC). Estas son: La Unión Campesina (UCC), La Comisión Zonal de Tierras (CZT) y la Asociación Cacique Taigoyic. Gran parte de esta población vive en los parajes rurales de Pampa del Indio, en especial, Campo Medina, Lote 4, Pampa Chica y Pampa Grande, donde desarrollamos este trabajo. La localidad se encuentra en el extremo norte del departamento Libertador General San Martín de la provincia del Chaco. La elección del lugar de estudio -y de estos parajes en particular- reside en la importancia política que tiene la zona en la conformación de movimientos sociales, en las acciones colectivas de protesta y en la lucha etnopolítica en distintos momentos de su historia. 
IMAGEN 1

Ubicación de la localidad de Pampa del Indio, mapa político de la provincia de Chaco

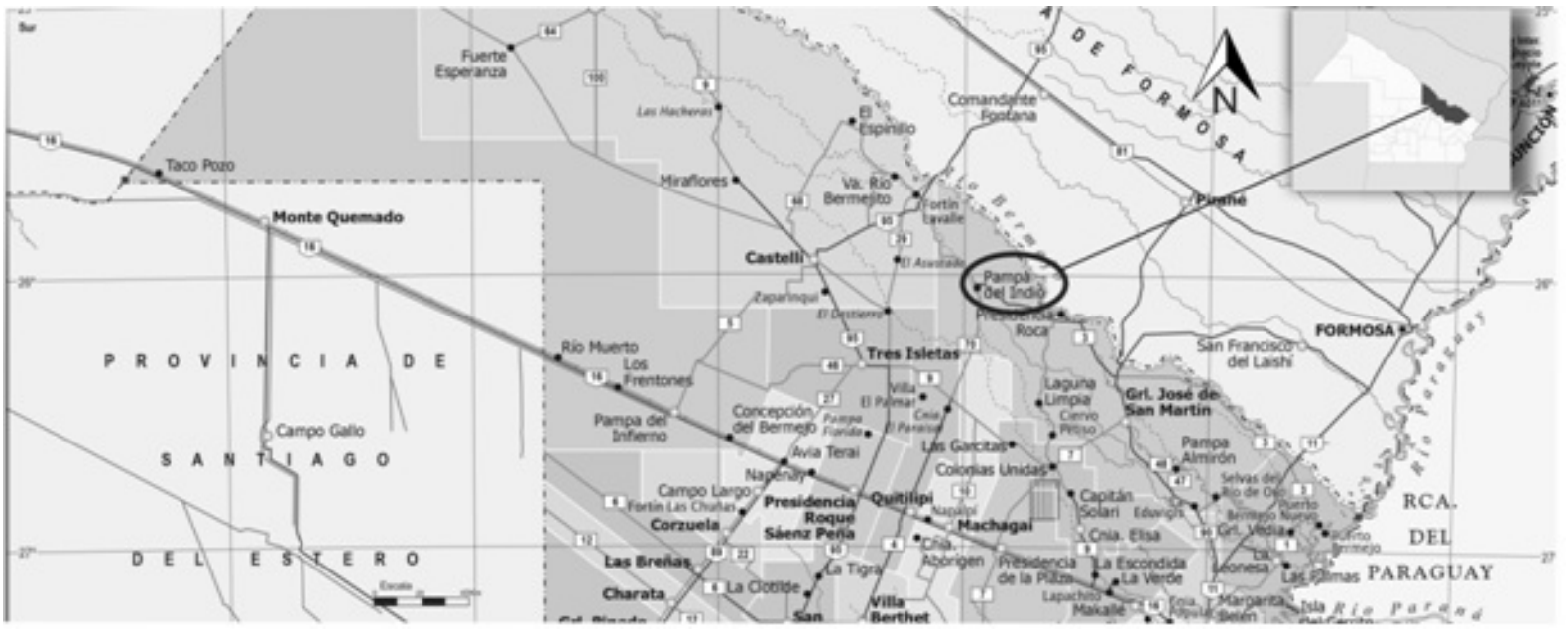

Fuente: Elaboración propia a partir de documentos del Instituto Geográfico Nacional.

El enfoque de abordaje es la etnografía. Se han realizado unas dieciséis entrevistas en profundidad a integrantes de la FNC; observación participante en asambleas, en diversas acciones colectivas y en reuniones con distintos representantes de organismos gubernamentales (Ministerio de la producción, Ejecutivo provincial). ${ }^{6}$ Además, para comprender la cotidianeidad de los sujetos y su concepción del cuidado de la naturaleza y la distribución de los alimentos, trabajamos con recorridos in situ junto a hombres y mujeres por sus chacras y cultivos. Esto abrió la posibilidad de indagar situaciones de la vida diaria que no necesariamente se enunciaban en las entrevistas y que fueron registradas en notas de campo aquí utilizadas.

Por último, recurrimos a comunicados de prensa difundidos por el movimiento social, artículos periodísticos y datos estadísticos (Censos Nacionales, Relevamiento socioproductivo realizado por la Federación Nacional Campesina) que contribuyeron a profundizar el análisis sobre las condiciones estructurales y de vida de estas poblaciones.

\section{Del Trabajo TEMPoral EN EL ALGODón A LA EXCLUSIÓN DEL SISTEMA PRODUCTIVo}

Durante gran parte del siglo XX las actividades económicas en el medio rural en la provincia de Chaco estuvieron principalmente diversificadas en tres ramas: la extracción forestal, el cultivo e industrialización de la caña de azúcar, y la producción algodonera. Esta última se extendió, con distintos momentos de auge y estancamiento, durante todo el período 192-199 y planteó características similares al resto de las economías regionales: producciones de base agraria, con predominio de explotaciones minifundistas, una especialización productiva generalmente intensiva en el uso de mano de obra y dependiente de la evolución del mercado interno (Rofman, 1999). Además, estuvo asociada a un rol activo del Estado en la promoción del cultivo, a la expansión y apropiación de tierras para la fundación de colonias agrícolas (Ley 4167) y a la utilización de grandes contingentes de fuerza de trabajo aborigen (Musante, 218). Todo esto funcionó para garantizar las demandas de un modelo productivo con destino a la exportación de materias primas (Slutzky, 2014).

En efecto, las labores inherentes al cultivo - carpida y cosecha- de algodón fueron íntegramente manuales hasta épocas relativamente recientes. De aquí la necesidad de una gran masa de los denominados "braceros" o "jornaleros" requeridos periódicamente por los propietarios de las explotaciones de mediana y gran escala. En su mayoría esta mano de obra era de origen local, principalmente de pueblos originarios. También se complementaban con migrantes de la provincia de Salta, Corrientes, Santiago del Estero y Santa Fe 
y de origen paraguayo. Estos contingentes formaron parte de desplazamientos migratorios masivos e involucraron, por ejemplo en los momentos más intensos de auge algodonero (1935-1936), un total de 129.639 trabajadores temporarios (Mari, 2009).

En la localidad de Pampa del Indio, la subordinación de las comunidades Qom como mano de obra a la economía algodonera estuvo relacionada con un particular proceso de sedentarización y territorialización a partir del acceso a la tierra, en 1924 . $^{7}$ Durante la carpida y cosecha gran parte de la población realizaba trabajos estacionales extraprediales -relativamente estables y retribuidos en dinero- en las chacras aledañas o migraban a localidades vecinas. Con posterioridad, regresaban a su territorio donde practicaban una economía doméstica sustentada en el acceso a los recursos naturales provenientes del monte y el río como la recolección, la pesca, la marisca y una incipiente agricultura. Estas actividades se complementaron con la producción agrícola favorecida por la implementación de programas estatales de colonización en el año 1946, a través de los cuales parte de la población accedió a insumos y herramientas para la producción agrícola en sus parcelas. ${ }^{8}$

En términos generales, durante el período algodonero (1920-1990), esta comunidad indígena mantuvo una doble condición de existencia: por un lado, como trabajadores asalariados temporales (semiasalariados) y como "ejército de reserva" para las necesidades de fuerza de trabajo del capital (Marx, 2008). Por el otro, como campesinos con prácticas agrícolas, de caza, pesca y recolección. Como menciona Trinchero (2000), esta condición de reservorio de mano de obra era pagado por la economía doméstica en sus territorios en un contexto de posibilidades de acceder a la tierra y desarrollar actividades productivas, lo cual habilitó distintos procesos de campesinización de estos pueblos. ${ }^{9}$ Vale destacar que la existencia de esta doble condición de los indígenas conformó un escenario bastante típico dentro de las economías regionales del norte argentino (Manzanal, 1990; Giarracca, 2017). ${ }^{10}$

Sin embargo, en las últimas décadas del siglo XX, las actividades de estas comunidades y los territorios atravesaron una profunda desestructuración. La apertura de la economía a la competencia externa, sumada a la desregulación estatal en los mecanismos de fijación de precios sostén de comercialización del algodón, y los cambios operados en la relación capital-trabajo, transformaron la dinámica de acumulación regional (Rofman, 1999). En la provincia de Chaco, emergieron megaproyectos agroindustriales, amparados en un fuerte soporte estatal. Los mismos estuvieron vinculados a la producción a gran escala de commodities para exportación (principalmente soja, arroz y ganadería) y a la intensificación de la actividad forestal extractivista (Brodersohn, Valenzuela y Slutzky, 2009).

$\mathrm{Al}$ respecto, la evolución de la superficie sembrada en la provincia entre 1995-2003 mostró un notable descenso del algodón acompañado del aumento de otros cultivos. La campaña algodonera 1995/1996 de 611.930 hectáreas (ha) sembradas con algodón fluctuó a 180.000 ha en 1999/2000 y a 85.000 ha en $2002 / 2003$. Mientras que la soja y el girasol fueron en aumento desde 55.000 y 76.000 ha respectivamente en $1995 / 1996$ a 170.000 y 280.000 ha en $1999 / 00$ y 253.000 y 586.000 en la campaña 2004/2005.

Las transformaciones a escala productiva para garantizar las nuevas condiciones de rentabilidad estuvieron determinadas por requerimientos de capital constante (fundamentalmente paquetes tecnológicos -insumos, semillas- relacionados a una mayor escala de producción) y a la disminución de capital variable (desplazamiento de mano de obra por mecanización).

En definitiva, esta nueva etapa generó un período extraordinario de producción de valor y acumulación de renta a la par que significó una mayor concentración de tierras y produjo consecuencias negativas en un amplio sector de productores, quienes encontraron serias dificultades para "adecuarse" a la nueva lógica agroindustrial. El Censo Nacional Agropecuario de 1988 registró que los sectores de mayor escala constituían el 7,5\% del total de explotaciones algodoneras, mientras que aquellas de hasta 500 hectáreas representaban el $92 \%$ restante. Sin embargo, en 2002 estos datos conformaban el $13 \%$ y el $86 \%$ respectivamente. ${ }^{11}$ 
Para los Qom de la localidad de Pampa del Indio, estas transformaciones tuvieron consecuencias aún más drásticas. Los cambios operados en la relación capital-trabajo desestructuraron la doble condición de existencia de los indígenas como trabajadores temporales y campesinos. Esto sucedió, por un lado, por el reemplazo por maquinaria de las labores manuales inherentes al cultivo y cosecha del algodón. También, por la eliminación de las políticas proteccionistas que impidieron la comercialización de la producción familiar de algodón de Campo Medina, por ejemplo. Esto generó un gran contingente de aborígenes en condiciones de desocupación y la desarticulación de su economía doméstica como campesinos, ya que esta se encontraba subsumida a su rol en el mercado de trabajo como asalariados. ${ }^{12}$

Por otro lado, se profundizaron los mecanismos de acumulación por desposesión en relación a la apropiación del espacio y la naturaleza (Harvey, 2004), a las que los indígenas mantenían un acceso relativamente "libre". El Estado incorporó al mercado grandes extensiones de tierras públicas que fueron privatizadas para terratenientes y grandes empresarios (muchos de ellos, de origen pampeano, que aprovecharon estas inversiones sustentadas en el relativamente bajo valor de la tierra en relación a otras regiones) y desmontadas para su puesta en producción. ${ }^{13}$ Esto significó un aumento de los desalojos (pese a las regulaciones legales que los prohíben, como la Ley 26.160) y el despojo de espacios de uso común de la comunidad (lagunas y ríos para pesca y marisca), con episodios de castigos hacia quienes pretendían utilizarlos. ${ }^{14}$ Incluso, los nuevos propietarios se apropiaron de espacios destinados a fines espirituales, como los cementerios, los cuales fueron objeto de una profunda violencia al ser destruidos y utilizados con objetivos productivos. En definitiva, la imposibilidad de estas poblaciones de desarrollar su economía doméstica y de continuar como trabajadores temporales, sumado a la autonomía relativa que mantenía una actividad con la otra, condicionó la subsistencia en los territorios y generó una doble exclusión de la población del sistema.

Si bien las familias Qom que habitan los parajes rurales de Pampa del Indio poseen los títulos de propiedad de sus parcelas, la privatización de tierras estatales impidió nuevos asentamientos de las familias extendidas, generando el hacinamiento demográfico dentro de los pequeños terrenos que quedaron bajo su control. ${ }^{15} \mathrm{En}$ el paraje rural de Campo Medina en el año 2014, por ejemplo, la densidad demográfica de tierras bajo posesión indígena se estimaba en 1,4 hectáreas/habitante, lo cual suponía una reducción sustancial comparada con las 10 hectáreas promedio que los Qom ponían en producción en el período algodonero y la media de 100 hectáreas de los campesinos criollos de la zona (FNC, 2014).

Todos estos cambios estructurales tuvieron consecuencias directas sobre la organización social y la vida cotidiana, incluyendo sus temporalidades vinculadas a: 1- los ciclos productivos (momentos de "salir" a cosechar); 2- La "crisis del pueblo indígena", como mencionaba uno de los entrevistados, que marcaba el momento de escasez de alimentos al regreso de los trabajos extraprediales (mayo-junio y agosto-octubre) y el inicio de actividades de caza y recolección y 3 - La escolaridad de los menores, la cual se realizaba de agosto a diciembre, al regreso a sus territorios.

En esta situación, los Qom emprendieron diversos caminos para garantizar su propia reproducción social. Las estrategias individuales y colectivas se fueron articulando a partir de su habitus (Bigot, Rodríguez y Vázquez, 1992; Bourdieu, 2014). Algunas de ellas consistieron en acciones de carácter individual, vinculadas a la búsqueda de actividades por fuera del ámbito rural, como el empleo estatal (tareas de limpieza pública, agentes sanitarios, etc.) y otras en el sector privado, en tareas como empleados o cuentapropistas (en general en condiciones de precariedad -changas-). Esto generó migraciones a la zona urbana de Pampa del Indio o a grandes ciudades (como Resistencia, Rosario, Buenos Aires o La Plata). En otros casos, la respuesta consistió en una apuesta por la reproducción social en su propio territorio a través de acciones colectivas que buscaron resolver de manera conjunta mejores condiciones de vida. En este camino, fueron recreando valores comunitarios propios de sus prácticas socioculturales que habían sido relativamente desarticulados por los procesos de subordinación económica y cultural. 


\section{SOLIDARIDAD ECONÓMICA EN LA PRODUCCIÓN FAMILIAR:}

Desde fines de la década de los 90 e inicios de los 2000, la acción colectiva de los indígenas del Chaco podría cuestionarse en términos analíticos similares a los empleados por E. P. Thompson (1991) en su estudio sobre la economía moral de la multitud inglesa: ¿Qué hace la gente cuando tiene hambre? ¿De qué forma las costumbres, la cultura y la razón modifican su comportamiento? En este caso, para resolver de manera colectiva estos dilemas, las comunidades Qom articularon dos tipos de acciones: repertorios de protesta social, en el marco de la beligerancia popular (Auyero, 2002) y la persecución de bienes e intereses comunes a través de actividades económicas habilitadas por recursos estatales y de asistencia social. ${ }^{16}$ En este sentido, a continuación se analizarán las experiencias de producción algodonera de las unidades familiares con destino a la comercialización a partir del Plan Nacional de Desarrollo Local y Economía Social "Manos a la Obra" y del programa de "Comercio justo" desarrollados en el período 2003-2011.

A partir de 2003, y luego de la crisis económica del año 2001 que generó problemas estructurales respecto al empleo e ingresos, el Estado nacional planteó transformaciones en la gestión pública de las políticas sociales. En términos generales, estas estuvieron destinadas a fortalecer marcos institucionales para el nuevo plan económico de aumento del consumo interno y a dirimir las tensiones políticas generadas entre los sectores populares y el Estado (Merklen, 2005). Mediante la oferta de una "cartera asistencial de recursos" centralizada desde el Ministerio de Desarrollo de la Nación (MDSN), se implementó una política territorial de asistencia, articulando a nivel local con movimientos sociales, ONG y otros organismos (Perelmiter, 2012). ${ }^{17}$ Así, diversas organizaciones políticas con trayectoria en la protesta social y en la demanda de asistencia se convirtieron en actores legítimos de la gestión de políticas sociales.

Luego de una movilización de desocupados, campesinos e indígenas realizada en Resistencia a fines del año 2002, el MDSN firmó un convenio en Pampa del Indio con las organizaciones participantes de aquel evento. El mismo consistía en la implementación del Programa Nacional de Desarrollo Local y Economía Social "Manos a la Obra" y la entrega de 80 toneladas de semillas, herramientas y combustible para que 850 familias cultiven algodón en las parcelas bajo su control (Semillas y herramientas para una comunidad toba del Chaco, diario La Nación, 2003). ${ }^{18}$ La canalización de recursos del Estado demandó a los beneficiarios la gestión de una personería jurídica. De aquí surgió en el paraje rural de Campo Medina la organización Unión Campesina bajo la figura de Asociación Civil. A lo largo de los años, la apropiación por parte de los Qom de esta entidad trascendió la lógica organizativa de la asociación (división jerárquica de tareas, individualización de sus integrantes, entre otras) y se articuló con prácticas políticas y económicas que fueron construyendo las familias en el territorio.

Para la participación en el proyecto productivo, en vez de optar por una lógica de distribución y administración individual/familiar de los recursos - como lo estipulaba dicho Programa-, los indígenas de Pampa del Indio desarrollaron una estructura política con fuerte anclaje territorial y comunitario. De esta manera, las decisiones sobre las tareas de organización de la producción (uso del tractor, parcelas a utilizar, etc.), la elección de las familias participantes y la distribución de los recursos se realizaban en espacios que trascendían los mecanismos institucionales estipulados. Se conformó un cuerpo de delegados basado en las relaciones de parentesco de las familias extendidas en cada paraje rural y se instaló la "asamblea" como mecanismo de debate y toma de decisiones. Si bien en principio esta dinámica organizativa tuvo origen en formas de participación surgidos en otros espacios políticos -como el movimiento de desocupados-, el sustrato colectivo planteado por la misma encontró afinidad en las pautas socioculturales de los Qom. ${ }^{19}$ Junto con esto, emergieron y se revitalizaron liderazgos indígenas (por ejemplo, con la figura del dirigente Qom, Mártires López), prácticas religiosas pentecostales (junto con pastores que también se incorporaron a la organización) y la adscripción de algunos dirigentes e integrantes del movimiento al Partido Comunista Revolucionario de Argentina (PCR). Además, la amplitud de participación a otros actores sociales -por 
ejemplo, profesionales solidarizados con las actividades o campesinos pobres no indígenas-, permitió el fortalecimiento de las relaciones interétnicas, a la par que permitió la apropiación de la lucha etnopolítica de los Qom por parte de estos sectores (Colla, 2015).

Para la organización de la producción de algodón y la división del trabajo, la unidad doméstica (compuesta por familias extendidas dentro de cada lote) estuvo orientada a resolver problemas de sobrevivencia, proporcionar beneficios comunitarios y satisfacer necesidades integrales colectivas. Las familias activaron prácticas de solidaridad económica, entendidas - desde los estudios decoloniales-como aquellas actitudes de unidad basadas en metas o intereses comunes, sumado a un planteamiento político de transformación social (Marañón-Pimentel, 2012). ${ }^{20}$ Estas acciones se ejemplifican en las experiencias locales de los Qom al momento de distribuir los recursos escasos (disponibilidad de maquinarias y herramientas), diagramar la división de tareas y planificar la cosecha manual de manera colectiva -sobre todo para ayudar en aquellos casos de familias de pocos integrantes-. De esta manera, luego de acuerdos obtenidos con el ejecutivo provincial en la Marcha del Impenetrable del año 2009, los campesinos Qom diseñaron un plan de arada para el uso y mantenimiento de los tres tractores disponibles, centralizaron las herramientas por lote para su uso comunitario y se conformaron "cuadrillas" para la cosecha colectiva.

Vale mencionar que estos pueblos han mantenido, dentro de los procesos de resistencia étnica, acciones de solidaridad y reciprocidad como rasgo cultural en sus relaciones sociales cotidianas y en sus prácticas de caza-recolección (Gordillo, 2006). Estas actitudes se manifestaron en este proceso al interior de la división del trabajo agrícola en las parcelas familiares. Es decir, como mecanismo articulador del conocimiento práctico de experiencias pasadas (referidos a los tiempos de arada, siembra y cosecha) y aquellos saberes nuevos que debieron ser aprendidos. Por ejemplo, las tareas administrativas (redacción de actas, carga de planillas de asistencia, gastos corrientes de gasoil, etc.) y laborales (elección y contratación de tractoristas). Estas actividades fueron asumidas por determinados participantes de los programas que fueron escogidos en asamblea. Como menciona uno de los técnicos de la FNC, quien actualmente coordina y atiende las tareas administrativas y bancarias en la oficina del movimiento en Pampa del Indio:

Allá por el 2003, estuve como secretario y no sé escribir un acta nada, sé escribir, pero no sé cómo se hace un acta. Entonces, después de eso me eligieron como comisión de la organización (...) y bueno de a poquito fuimos aprendiendo como delegado (entrevista a Patricio, Pampa del Indio, enero 2018).

Las experiencias de comercialización son un último eje que nos interesaría analizar en este apartado. En un contexto de doble exclusión de estas poblaciones, las estrategias de producción algodonera en las parcelas indígenas se desarrollaron en un período de crisis económica. Las posibilidades de venta en cada campaña estuvieron condicionadas por la desregulación estatal para fijar precios mínimos y pautas de comercialización -por ejemplo, diferencias de retribución monetaria según cosecha manual o de maquinaria-. Asimismo, en determinadas ocasiones no fueron compensatorias -en lo económico- del trabajo y el esfuerzo realizado. Sin embargo, para estos productores constituyó una experiencia nueva de venta en el mercado y de retribución en dinero, a la par que construyeron nuevas subjetividades en torno al trabajo propio y la autonomía. Por ejemplo, un entrevistado reflexionaba:

(...) Esa vuelta en la chacra sembrábamos algodón. Y ahí poder tener la platita y eso por lo menos ya es un trabajo que es tuyo, no es del patrón. Ahí ganas más (...) Pero ya es tu producción. Entonces ponele que $\$ 10$ si vendes. Un valor de $\$ 10$ le quedaba $\$ 8$ al patrón y vos lo que cosechaste te daba, a lo mejor, $\$ 2$, algo así. Pero si es una producción que vos mismo sembraste, vos mismo cosechaste, te ganas toda esa plata. Los $\$ 10$ (...) cómo te puedo decir, ya es tu plantita (...) a la chacra la que tenés que limpiar, tenés que cuidar, pero ya es nuestro, no es del patrón. Y así fue. Y ahí empezamos, despertamos, pero no pudimos continuar de sembrar más hectáreas porque no teníamos más mercadería para comer (Entrevista a Patricio, Pampa del Indio, enero 2018).

En aquellas experiencias del 2003, por ejemplo, bajo condiciones climáticas adversas (una intensa sequía echó a perder el 50 \% de la siembra), la comercialización del producto duplicó el ingreso anual de las familias 
en relación al que recibían por trabajos extraprediales. ${ }^{21}$ Luego, en el año 2006 los dirigentes de la FNC realizaron un acuerdo anual con organismos internacionales para comercializar la fibra del algodón bajo el programa de "Comercio justo". Esto formó parte de un circuito mayor de la cadena productiva local e internacional, ya que se suministraba materia prima a una fábrica recuperada en la provincia de Buenos Aires y a más de 300 tiendas de ropa en Italia a través de la empresa CTM-altromercato. Si bien estas vinculaciones mercantiles no prosperaron por la desarticulación del programa, en las subjetividades de los campesinos Qom estas experiencias se instalaron como alternativa comercial y construyeron sentidos y perspectivas políticas de cooperación con otros actores sociales.

Lo paradójico de estas prácticas económicas de los campesinos es que si bien se organizaron bajo una racionalidad no capitalista (aunque mantuvieron determinadas relaciones asalariadas, por ejemplo, con el tractorista) no estuvieron alejados de la lógica del capitalismo. Por caso, en el proceso de mercantilización de su producción y en la negociación de los precios de venta. Como veremos en el próximo apartado, este particular ethos económico dado por la situación de integrar -bajo subordinación- la cadena agroindustrial como proveedores de materia prima, cambiará drásticamente cuando las condiciones estructurales de exclusión alejen a estos productores de los mercados. Esto transformará su vinculación con la lógica capitalista y potenciará una racionalidad campesina similar a aquella planteada en los estudios clásicos de Chayanov (1974 [1925]). Es decir, el supuesto de que la unidad familiar es simultáneamente una unidad de producción y de consumo, en la cual el principal objetivo es la satisfacción de las necesidades de la familia.

\section{IMAGEN 2}

Fotografía de una cosecha de algodón. Mártires López junto a su familia. Campo Medina, 2004

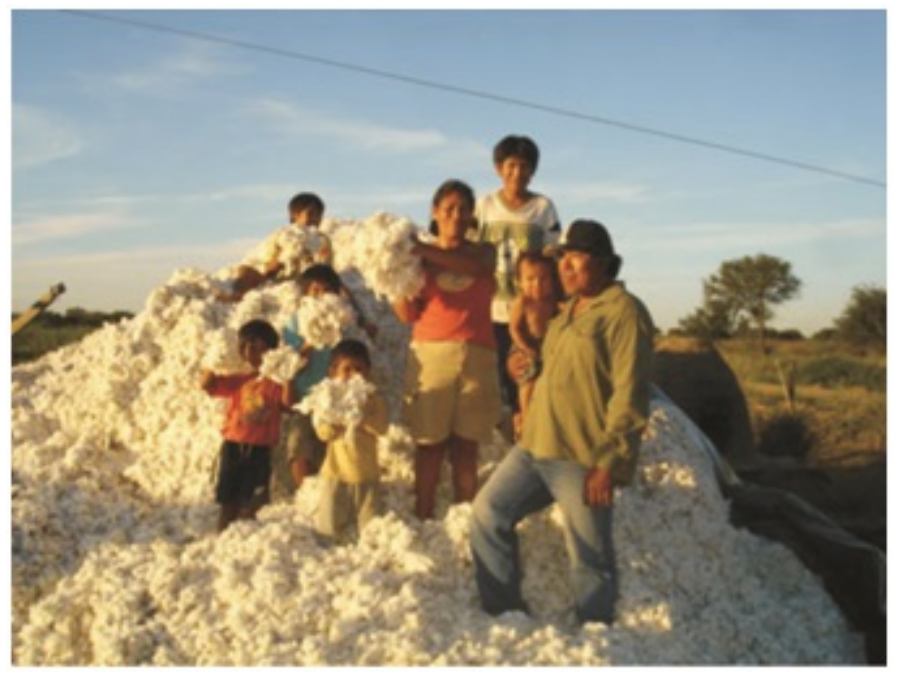

Fuente: Federación Nacional Campesina.

En efecto, distintos factores políticos, económicos y étnicos se convirtieron en 2011 en determinantes para la desestructuración de estas actividades y el fin del período aquí analizado: por un lado, la desarticulación del mercado algodonero y la eliminación de los programas productivos; por otro, las fumigaciones con agrotóxicos en producciones de soja en parcelas vecinas, junto con una intensa sequía que se prolongó por los siguientes seis años. ${ }^{22}$ Esto provocó graves secuelas en los cultivos y a la salud de los pobladores. Por último, finalizada la Marcha del Impenetrable en junio de 2011, el dirigente de la FNC, Mártires López, falleció en un accidente vial que el movimiento social denunció como atentado. Esto último fue determinante ya que se desarticuló la organización política y trasladó el centro de las demandas al pedido de justicia por su líder político.

En definitiva, estas experiencias de organización autogestionaria dejan planteada la posibilidad de que un conjunto de sujetos, en contexto de exclusión del espacio económico y social, puedan modificar su 
condición preexistente y crear otra situación. Las poblaciones beneficiarias de Pampa del Indio debieron cumplimentar determinados requisitos formales para la autogestión, a la par que activaron acciones y saberes, hábitos compartidos, aprendidos e improvisados, para la organización comunitaria. Este habitus (Bourdieu, 2007) propio de sus experiencias, fue central para recibir y administrar el dinero y los insumos, organizar la división del trabajo y comercializar el algodón. $\mathrm{Al}$ respecto, consideramos que el conjunto de estas prácticas agrícolas fueron resignificadas por los campesinos indígenas con el objetivo de alcanzar beneficios colectivos y fortalecer su etnicidad. Es decir, se convirtieron en estrategias etnopolíticas que fueron visibilizadas y fortalecidas por los movimientos sociales para la construcción política y la vinculación con otros sectores sociales. Y a partir de las cuales se pudieron aprovechar derechos específicos y buscar apoyo de organismos del Estado, como el INTA.

En todo lo analizado hasta el momento, la organización aparece como un punto crítico, ya que es aquí donde surgen nuevas necesidades y destrezas (aprender a escribir un acta, manejar una computadora) y la búsqueda de soluciones colectivas frente a las restricciones (materiales, como es la disponibilidad de tierra y el acceso a la alimentación). En este sentido, organizarse comunitariamente tiene un fin utilitario de superar problemas de escasez de recursos y supone un espacio permanente para la generación de estrategias económicas con fuerte componente de solidaridad y reciprocidad.

Retomando a E. P. Thompson (1991) podríamos decir que estas prácticas parten de actitudes que no tienen lugar entre personas desamparadas o sin esperanzas, más bien pertenecen a aquellas que se percatan de su poder de transformación social. En este sentido, no debería interpretarse como una respuesta cultural de las poblaciones indígenas ni de "adaptación" a las condiciones de pobreza, sino una pauta compleja de comportamiento, una alternativa colectiva a las estrategias de supervivencia individuales y familiares. Aquí también reside la posibilidad de pensar la creación de nuevas institucionalidades políticas, diferentes a la del Estado, y en proyectos que trasciendan lo asistencial y coyuntural, con racionalidades económicas diferentes a las del capital (Marañón-Pimentel, 2012).

\section{"RECIBIR, PEDIR Y COMPARTIR": LAS EXPERIENCIAS DE PRODUCCIÓN AGRÍCOLA COMUNITARIA}

En el año 2016 las poblaciones indígenas en el Chaco conformaban los sectores (urbanos y rurales) más pobres de Argentina. ${ }^{23}$ En Pampa del Indio, el deterioro en las condiciones de vida, producto de la intensa sequía y el abandono de las actividades productivas, generó situaciones sanitarias y sociales críticas. ${ }^{24} \mathrm{Si}$ bien la demanda de insumo de agua se ubicó en el centro de los reclamos políticos de los sectores rurales, el aumento de las precipitaciones hídricas a mediados de aquel año motivó a los indígenas a regresar a las prácticas campesinas. Estas se ampararon en la necesidad de superar los limitantes económicos impuestos por la coyuntura social y en la voluntad de recrear estrategias colectivas de reproducción social al igual que en las últimas campañas algodoneras. Por esta razón, en este apartado se analizarán las actividades económicas realizadas por los Qom de Pampa del Indio desde el 2016 hasta la última cosecha en 2018, vinculadas a la producción agrícola y hortícola destinada al autoconsumo. A diferencia del período previo (2003-2011), estas experiencias fueron resueltas con medios de producción y recursos mínimos e íntegramente comunitarias. De esta manera, las actividades cotidianas para organizar las huertas, aprender las tareas de cuidado de una chacra, improvisar para resolver la escasez de herramientas y distribuir los alimentos entre los vecinos, formaron parte de la mimesis práctica de estos sujetos (Bourdieu, 2007).

Asimismo, estas acciones estuvieron mediadas por relaciones de intercambio basadas en un principio de reciprocidad: "recibir", "pedir" y "compartir". Con esto, nos referimos específicamente a actos cotidianos de intercambio de favores en la distribución de alimentos que suelen involucrar a todos los miembros de la comunidad y se realizan sin intermediación del mercado (Gordillo, 2006). Como analizamos al final de 
este apartado, estas actitudes también imponen límites a las formas internas de acumulación y diferenciación social a partir de la presión social distributiva para el consumo de los productos.

En primer lugar, en relación a la asistencia estatal en comparación con el período anterior, se desarticuló la dinámica "Estado-programas-movimientos sociales". El Estado Nacional planteó una política de programas de asistencia desvinculadas de las actividades económicas en el ámbito rural junto al desfinanciamiento de organismos agropecuarios a nivel nacional (como el INTA). ${ }^{25}$ Esto demandó que los campesinos Qom que integran la FNC deban implementar mecanismos para "adecuarse" a los perfiles formales de los beneficios (por ejemplo, programas para finalización de los estudios y para aprender oficios como el "Argentina Trabaja” y "Hacemos futuro" ${ }^{26}$ ) y buscar financiamientos alternativos. Por caso, un campesino de Pampa Chica describía cómo se había organizado con sus compañeros para juntar el dinero entre las familias que percibían determinados planes y comprar 500 metros de alambre para el proyecto de huerta comunitaria en su chacra. Asimismo, el técnico de INTA de la zona contribuía con asistencia técnica y con la disponibilidad del tractor para realizar tareas de arada (entrevista a Jorge López, Pampa Chica, enero 2018).

Si bien la solidaridad económica continuó siendo articuladora de las actividades productivas, la organización de la producción debió afrontar determinados problemas materiales que se habían profundizado en los últimos años, como el hacinamiento poblacional y la deficiente infraestructura (cercos y herramientas dañadas, etc.). Por lo tanto, a través de asambleas en los parajes rurales, la FNC resolvió realizar nuevas experiencias de producción agrícola y hortícola de manera íntegramente colectiva, bajo dos modalidades: la primera, materializada en un semillero comunitario en la ciudad de Castelli que contó con la participación de familias Qom de distintas localidades y con la solidaridad de otros sectores sociales. Y la segunda, bajo huertas comunitarias llevadas a cabo en Pampa del Indio y nucleadas en la organización interna de las familias en cada paraje rural.

Por un lado, la experiencia del semillero comunitario realizado en 2017 tuvo como objetivo pragmático generar mayor autonomía para la adquisición de insumos, ya que los percibidos a través de acuerdos con las agencias estatales llegaban a destiempo o eran inadecuados para las condiciones agroambientales de cada zona. ${ }^{27}$ El predio de 8 hectáreas para el cultivo fue cedido bajo comodato por un productor de Castelli. A su vez, los insumos fueron adquiridos en semilleros agroecológicos pertenecientes a campesinos guaraníes de la provincia de Misiones y el gasoil fue suministrado por convenios directos con el Estado. La cosecha se llevó a cabo de manera manual en agosto de ese año con cuadrillas de 120 personas provenientes de los distintos parajes rurales -entre ellos, de Pampa del Indio-. Finalmente, se desgranaron y embolsaron 4.500 kilos que fueron distribuidos entre 1.400 integrantes de la FNC para la campaña agrícola 2017-2018. En aquellas jornadas, un comunicado de la organización, titulado "Una cosecha de 15 años de lucha para no irnos del campo", demandaba al gobierno provincial los fondos necesarios para replicar estas experiencias y generar circuitos de comercialización. ${ }^{28}$

La singularidad de esta experiencia fue que estas prácticas circularon por fuera de los estándares de productividad y eficiencia propios de una producción capitalista. La búsqueda de insumos sin manipulación genética, el reemplazo de la maquinaria por tareas manuales de cosecha -incluso de desgrano- y la distribución equitativa de la misma entre los participantes, son ejemplos que podrían plantearse como pautas "anti-económicas" bajo los estándares convencionales. De hecho, estamos en presencia de actividades que se encuentran por fuera de la ley del valor (producción con destino al autoabastecimiento), que desmitifican la tecnología y los parámetros de productividad e independizan a los campesinos de la lógica capitalista. 
IMAGEN 3

Fotografía de la cosecha del semillero comunitario. Castelli, 9 de agosto de 2017

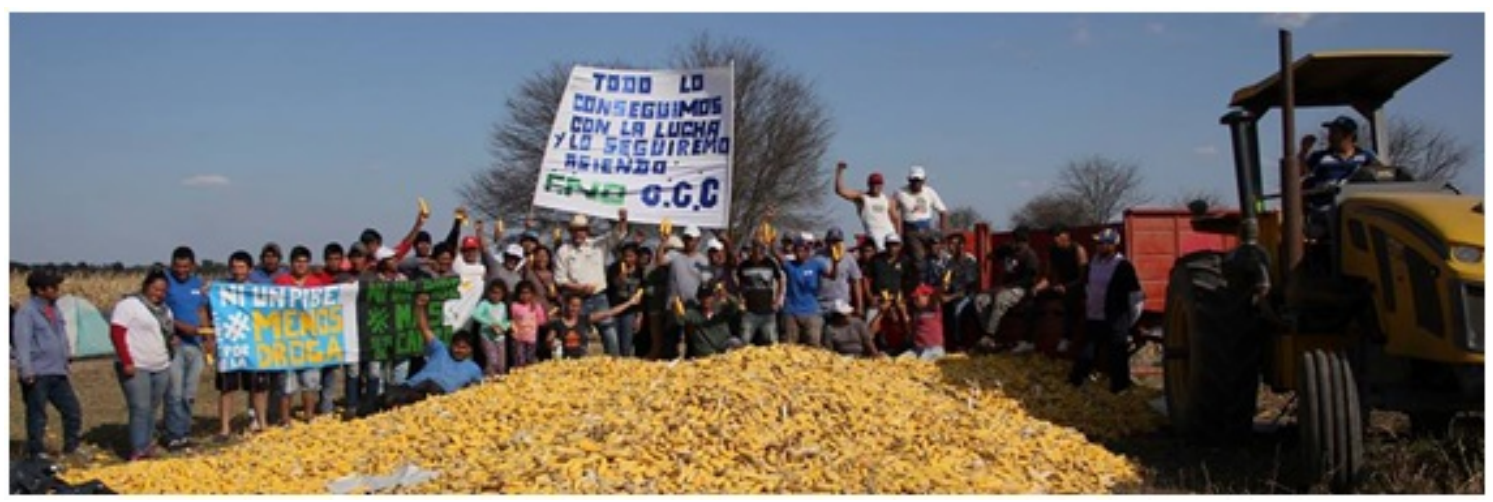

Fuente: Federación Nacional Campesina.

Por otro lado, las huertas comunitarias se llevaron a cabo en Pampa del indio a fines de 2017 y consistieron en doce proyectos situados en distintos parajes. Las actividades fueron realizadas en parcelas familiares designadas en asamblea según las condiciones productivas (calidad del suelo, acceso al agua, etc.). En principio, la producción se organizó bajo un esquema de trabajo colectivo de hombres y mujeres y se dividieron las tareas: construcción de cercos, arada y siembra, tareas de cuidado y distribución de alimentos con destino al autoconsumo. Al respecto, Jorge, un campesino Qom del paraje de Pampa Chica, comentaba:

Y siempre nos reunimos, nos organizamos, así somos los Qom (...) Desde hace un par de años que hacemos [la producción] (...) Mártires nos enseñó este camino, y bueno, ahora estamos siguiendo. Cuando ese compañero estaba nos enseñó esta forma comunitaria para hacer, para trabajar. Y sí porque vos sólo no puedes hacer nada, porque necesitas. Tenés que cortar los postes, hacer los pozos para poner el poste. Necesitas un grupo y si vos estas sólo no vas a hacer nada. Es la enseñanza que nos quedó (Entrevista a Jorge López, paraje Pampa Chica, enero de 2018).

Este discurso pone de manifiesto los sentidos que estructuran el habitus de los campesinos Qom a partir de la confluencia, por un lado, de saberes socioculturales del grupo étnico ("nos organizamos" porque "así somos"); por otro, de conocimientos aprendidos en las experiencias de producción agrícola previas ("es la enseñanza”). Además, estas se encuentran atravesadas por el valor simbólico -cosmológico- que posee el dirigente post mortem, lo cual ha sido analizado en trabajos previos como parte del capital simbólico del grupo e inseparable de su sentido práctico (Colla, 2015). Asimismo, al no funcionar sobre un código de reglas estructuradas, las actividades hortícolas no fueron estrictamente homogéneas para todos. Incluso, los participantes solían vivirla y enunciarla de manera diversa. Por ejemplo, insertas en el dominio de la vida cotidiana y de cierta "habitualidad", las tareas destinadas al cuidado del cultivo y el consumo de los alimentos no fueron precisamente expresadas en las entrevistas que realizamos. Más bien, encontramos en los recorridos in situ junto a hombres y mujeres campesinas por las chacras, la riqueza de un sistema de clasificación que radicaba en cómo se lo actuaba en la práctica. En nuestras notas de campo pudimos describir la fisonomía que tenían las huertas en relación con el cuidado de la naturaleza y el cultivo, los saberes respecto a la manera de circular por los senderos e identificar las hortalizas y plantas medicinales y las racionalidades en la extracción y consumo de los alimentos. ${ }^{29}$ 


\section{IMAGEN 3}

Fotografía de Lelia López en la huerta comunitaria. Campo Medina, 2018

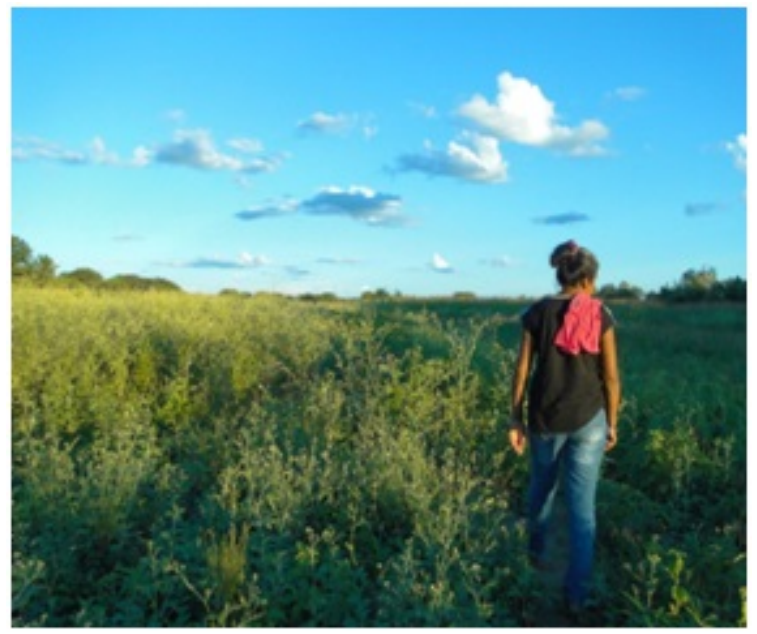

Fuente: Fotografía perteneciente a la autora.

A partir de estos recorridos, encontramos que el intercambio de alimentos mediados por lazos de reciprocidad era habitual entre los miembros de la comunidad. Si bien la actitud de indígenas de acercarse a "pedir" alimentos de la huerta y de "convidar" por parte de los productores está mediada por discursos de generosidad hacia el resto, se evidenciaba cierta presión por la sanción social de "no convidar" e identificarse como un "mal hermano". Al respecto, existen numerosas investigaciones que plantean que la diferenciación social de las unidades domésticas (dada por sus posibilidades de acumulación de capital o de la posesión de ciertos bienes materiales), puede encontrarse limitada por las relaciones sociales donde se inserta y generar condiciones hacia el igualitarismo (Scott, 1976). Bajo este marco, Gordillo (2006), en su trabajo sobre la reciprocidad y el acceso al empleo de los Qom de la provincia de Formosa, critica la visión antropológica de los cazadores-recolectores desde un prisma romántico occidental que naturaliza en ellos utopías igualitarias. Por el contrario, sostiene que este tipo de relaciones de intercambio han sido reconfiguradas a partir de la incorporación de estos grupos a las relaciones capitalistas, y las ubica como un mecanismo de presión distributiva mediada por la sanción social. En este sentido, las unidades domesticas más desfavorecidas materialmente son quienes pondrían en obligación de compartir a quienes poseen una diferenciación cuantitativa en términos de bienes.

En el caso de los Qom de Pampa del Indio nucleados en la FNC estas relaciones de intercambio generan una presión distributiva, y por lo tanto una contradicción, entre quienes acceden a los alimentos del trabajo comunitario de las huertas, y quienes no. Pero los participantes de los proyectos buscan resolver el conflicto, no desde sus intereses individuales (no compartir), sino apelando al espacio político y colectivo. Por ejemplo, en conversaciones sobre este tema con un campesino y dirigente del movimiento social, nos planteaba que su objetivo era que todos sus vecinos se incorporen a la lucha política para tener su propia chacra. También sucede algo similar en las convocatorias a las acciones colectivas (cortes de ruta, asambleas), en las cuales se recurre a las radios locales que funcionan como el principal mecanismo de difusión. Al respecto, consideramos que esto construye entre los Qom un horizonte de "nivelación" para resolver el intercambio de alimentos y conseguir mejores condiciones de existencia para la población Qom en su conjunto. En este sentido, en las estrategias productivas, la actitud de "pedir" se traslada de la presión moral de "convidar", a la presión política de "compartir" los alcances de la acción política. Esto permite reflexionar sobre la conciencia política colectiva que han construido estos pueblos, su etnicidad, y el horizonte de acción colectiva que plantean para sobrepasar las condiciones de extrema pobreza socioeconómica y garantizar su reproducción social. 


\section{Conclusiones}

En este trabajo analizamos, desde una perspectiva sociológica, las estrategias de reproducción social que utilizan los campesinos Qom de Pampa del Indio (Chaco) para enfrentar la lógica de doble exclusión que impone el desarrollo del capital en sus territorios. Por ello, describimos la manera en que estas poblaciones se apropiaron de los programas de asistencia estatal e implementaron diversas estrategias para realizar prácticas campesinas vinculadas a la producción agrícola y hortícola.

Consideramos que el análisis de estas actividades permite comprender que el objetivo de estas comunidades es la reproducción social de la vida, la cual no se halla anclada a las nociones de rentabilidad, competencia en el mercado o acumulación de capital. En este sentido, las poblaciones indígenas se reapropiaron de manera práctica de los programas estatales, para imprimirles una lógica diferente en base a sus formas de pensar, obrar y sentir propias de su identidad étnica y posición en la estructura social. De esta manera, las prácticas campesinas de estos indígenas habilitaron una mayor autonomía económica, en comparación con aquella que tenían bajo la doble condición de trabajadores temporales y campesinos en el período algodonero. A la par, estas prácticas permitieron fortalecer su pertenencia comunitaria y reafirmar su identidad étnica como campesinos Qom.

Es aquí donde los movimientos sociales y sus acciones colectivas aparecen como facilitadores de la lucha etnopolítica. En el espacio político de la Federación Nacional Campesina, la utilización estratégica de los derechos específicos como indígenas para reclamar la incorporación a programas estatales, la acción de unirse, solidarizarse con otros y la resignificación de los lazos de reciprocidad y de solidaridad económica son los ejes articuladores de la construcción de etnicidad. Esto resulta clave para que adquiera sentido político su identidad étnica.

En el primer período analizado (2003-2011), la organización de la producción algodonera apareció como central para poder superar los problemas de escasez de recursos y adecuarse a los requisitos del programa estatal Manos a la obra. De aquí que los campesinos Qom se reapropiaron del espacio institucional para conformar la FNC e instalaron estrategias de solidaridad económica para la organización de las actividades. Esta no sólo funcionó como mecanismo articulador de tareas del trabajo colectivo, sino también puso de manifiesto el conocimiento práctico de estas poblaciones. Por último, dejamos planteado el debate respecto a la posibilidad de pensar en estos contextos de exclusión, sociabilidades basadas en la reciprocidad/solidaridad entre las personas, en la creación de nuevas institucionalidades políticas y en proyectos que trasciendan lo asistencial y coyuntural, con racionalidades económicas diferentes a las del capital (Marañón-Pimentel, 2012).

En el segundo período (2016-2018) describimos las prácticas agrícolas y hortícolas que realizaron los campesinos Qom con destino al autoconsumo de alimentos. A diferencia de la producción algodonera previa, estas fueron íntegramente comunitarias y estuvieron mediadas por relaciones de intercambio basadas en un principio de reciprocidad: "recibir, pedir y compartir". Al respecto, planteamos que estas relaciones de intercambio generan una presión distributiva, y por lo tanto una contradicción entre quienes acceden a los alimentos del trabajo comunitario, y quienes no. Sin embargo, en la particularidad de las personas que integran la FNC de Pampa del Indio, la actitud de "pedir" se traslada de la presión de "convidar" a la de "compartir" los alcances de la acción política. Esto tiene como objetivo incorporar al conjunto del pueblo Qom a la lucha etnopolítica por mejores condiciones de existencia y ampliar el horizonte de acción y producción para la reproducción de la vida.

\section{BiBLIOgRAFíA}

Auyero, J. (2002). La protesta. Relatos de la beligerancia popular en la Argentina de los noventa. Buenos Aires: Libros del Rojas. 
Bigot, M., Rodríguez, G. y Vázquez, H. (1992). Acerca de la resistencia étnica y de la resistencia indígena. Papeles de Trabajo, 2.

Bourdieu, P. (2007). El sentido práctico. Buenos Aires: Siglo XXI.

Bourdieu, P. (2014) Las estrategias de la reproducción social. Buenos Aires: Siglo XXI.

Brodersohn, V., Valenzuela, C., y Slutzky, D. (2009). Dependencia interna y desarrollo. El caso del Chaco. Resistencia: Librería La Paz.

Chayanov, A. (1974) [1925]. La organización de la unidad económica campesina. Buenos Aires: Nueva Visión.

Colla, J. (2015). Aqui se respira lucha: prácticas políticas de los campesinos originarios qom de la Uinión Campesina de Chaco (Tesina inédita de grado). Universidad Nacional del Litoral, Facultad de Humanidades y Cs., Santa Fe, Argentina.

Giarracca, N. (2017) [1990]. El campesinado en la Argentina: un debate tardío. En Estudios rurales y movimientos sociales: miradas desde el Sur. Antología esencial. (pp. 332-343). Buenos Aires: CLACSO.

Gordillo, G. (2006). En el Gran Chaco. Antropologias e historias. Buenos Aires: Prometeo.

Harvey, D. (2004). El “nuevo” imperialismo: acumulación por desposesión. En Socialist register (pp. 99-129). Recuperado de: https://goo.gl/YhoLGP

Manzanal, M. (1990). El campesinado en la Argentina: un debate tardío o políticas para el sector: una necesidad impostergable. Realidad Económica, 97.

Marañón-Pimentel, B. (2012). Hacia el horizonte alternativo de los discursos y prácticas de resistencias descoloniales. En B. Marañón-Pimentel (coord.), Solidaridad económica y potencialidades de transformación en América Latina (pp. 125-155). Recuperado de: https://bit.ly/2Ltb5e7

Mari, O. (2009). La transición entre dos ciclos y sus efectos sociales en un territorio argentino. Revista de Geografía Norte Grande, 42, 21-40.

Marx, K. (2008) [1867]. El Capital. México DF: Siglo XXI.

Merklen, D. (2005). Pobres ciudadanos: Las clases populares en la era democrática (Argentina, 1983-2003). Buenos Aires: Ed. Gorla.

Musante, M. (2018). Reducir y controlar. Masacres, disciplinamiento y trabajo forzado en las reducciones estatales para indígenas de Chaco y Formosa durante el siglo XX. En W. Delrío et al. (coomps), En el país de nomeacuerdo (pp. 241-280). Buenos Aires: Ed. UNRN.

Perelmiter, L. (2012). Burocracia, pobreza y territorio: la política espacial de la asistencia en la Argentina reciente. Trabajo presentado en las VII Jornadas de Sociología. Universidad Nacional de General Sarmiento, Argentina.

Quijano, A. (2011).¿Sistemas alternativos de producción? En B. De Sousa Santos (comp.), "Producir para vivir" Los caminos de la producción no capitalista (pp. 369-397). México: FCE.

Rofman, A. (1999). Las economías regionales a fines del siglo XX: los circuitos del petróleo, del carbón y del azúcar. Buenos Aires: Ariel.

Santos, M. (2011). Producir para vivir. Los caminos de la producción no capitalista. México: FCE.

Scott J. (1976). The Moral Economy of the Peasant. Connecticut: Yale University Press.

Slutzky, D. (2014). Estructura social agraria y agroindustrial del nordeste de la Argentina. Posadas: Universitario.

Thompson, E. P. (1991). La economía moral revisada. En Cuestiones en común (pp. 294-394). Barcelona: Ed. Crítica.

Trinchero, H. H. (2000). Los dominios del demonio. Buenos Aires: Eudeba.

Tola, F. (2019) No-humanos que hacen la historia, el entorno y el cuerpo en el Chaco argentino. Etnográfica, 23(2), 489-513.

Valenzuela, C. y Scavo, A. (2009). La trama territorial del algodón en el Chaco. Buenos Aires: La Colmena.

Vázquez, H. (2000). Procesos identitarios y exclusión sociocultural. La cuestión indígena en Argentina. Buenos Aires: Biblos.

Wright, P. (2008). Ser-en-el-sueño. Crónicas de historia y vida toba. Buenos Aires: Biblos. 


\section{Artículos PERIODísticos}

Semillas y herramientas para una comunidad toba del Chaco (21/10/03). Diario La Nación. Recuperado de: https: //goo.gl/nqqveU

Una Cosecha que renovó la esperanza (1/03/04). Diario La Nación. Recuperado de: https://goo.gl/NfYj67

La vida fumigada (23/09/2015). Revista La Vaca. Recuperado de: https://goo.gl/xZyNcq

Exitosa cosecha: "Luchamos hace 15 años para no irnos del campo" (8/09/17). Diario Chaco día por día. Recuperado de: https://bit.ly/2KpIuFZ

Argentina: INTA en crisis presupuestaria y con ajustes (29/03/19). Prensa de APINTA. Recuperado de: https://bi t.ly/2DPyNe9

\section{INFORMES Y OTROS}

Argentina. Instituto Nacional de Estadísticas y Censos (2010). Censo Nacional de Población, Hogares y Viviendas. Argentina: Dirección de estudios básicos. Departamento de hidrología superficial (2017). Informe: Precipitaciones mensuales provincia del Chaco período 1956-2017.

Desarrollo Social de la Nación (2019). Programa Hacemos futuro. Recuperado de: https://bit.ly/2vzMF7X

Federación Nacional Campesina (2014). Relevamiento socio-productivo a comunidades campesinas indígenas. Informe (inédito). Ley provincial No 3258. De las Comunidades Indígenas.

\section{Notas}

1 En línea con investigaciones previas (Colla, 2015), tomaremos como tema de estudio al pueblo Qom, que representa el $74,5 \%$ de la población indígena de la provincia de Chaco y es uno de los que posee mayor desplazamiento territorial y éxodo rural interno de la región del noroeste argentino (INDEC, 2010).

2 La Federación Nacional Campesina (FNC) es un movimiento social que tuvo su origen en 2010 en la provincia de Chaco a partir de la confluencia de distintas organizaciones políticas. Ya en el 2003, en los parajes rurales de la localidad de Pampa del Indio, las familias indígenas crearon la agrupación Unión Campesina que luego se uniría a la FNC junto con otras de la zona como la Asociación Cacique Taigoyic y la Comisión Zonal de Tierras. Fuente: Artículo periodístico: "Se fundó la Federación Nacional Campesina de Argentina" publicado por Semanario Hoy 2/10/10. Recuperado de: https://bit.ly/2Lm195S

3 En este artículo utilizamos el concepto de etnicidad para referirnos al nivel macro de la identidad étnica que enfatiza los rasgos culturales en la construcción político-ideológica. Al respecto, Héctor Vázquez (2000) retoma la idea de que la misma es la identidad en acción resultante de una definida "conciencia para sí" que se pone de manifiesto de forma exponencial en las rebeliones y movilizaciones tradicionales o en las nuevas organizaciones etnopolíticas. Este concepto es parte de la identidad étnica (o "procesos étnicos identitarios") y refiere a una particular identidad colectiva, heterogénea y contiene múltiples dimensiones psicolingüísticas y socioculturales. Es la forma que asumen las contradicciones materiales y simbólicas dentro de un campo de interacción socioétnico relativamente acotado en el seno de una formación histórico social y durante un momento dado de las relaciones interétnicas. Esta situación no engendra relaciones opuestas, sino desiguales y basadas en el dominio/ sometimiento.

4 En este trabajo se utilizan indistintamente los términos pueblo indígena, originarios o Qom. Hacemos lo mismo con los términos de pueblos o comunidades. Este uso no conlleva un desconocimiento del origen colonial de algunos de ellos, ni tampoco el hecho de que estas variaciones responden a la historia de las relaciones que los países o sectores colonizadores han sostenido con dichos pueblos.

5 Nos referimos específicamente a las formas de interacción y a la cosmovisión que tienen los Qom sobre el monte y la naturaleza. Según Tola (2019), en la vida cotidiana de estos pueblos se entablan vínculos y comunicación con animales, plantas, fenómenos atmosféricos y otros seres no-humanos que son centrales para la vida de los Qom. De hecho, para los pueblos amerindios en general, estas entidades se presentan como sujetos sintientes, conscientes y activos interlocutores de un sistema de comunicación y, por lo tanto, no deben ser concebidos bajo una racionalidad instrumental. Para profundizar sobre el tema ver los trabajos de Tola (2019) y Wright (2008). 
6 Es necesario aclarar que en las citas textuales de las entrevistas que hemos incorporado en el texto se han respetado las expresiones lingüísticas de las personas (esto incluye determinadas variaciones de tiempos verbales o expresiones de uso cotidiano).

7 En el contexto de la lucha etnopolítica de las comunidades Qom de Pampa del Indio, en 1924 el Cacique Taigoyic obtuvo por parte del gobierno nacional el acuerdo de entrega de veinte mil hectáreas bajo la imagen legal de "Reserva Aborigen". Sin embargo, posteriormente aquel territorio se redujo drásticamente por la falta de mensuras del predio y por procesos de colonización de familias de criollos.

8 En 1946, el Cacique Pedro Martínez (líder político y religioso pentecostal) consiguió en negociaciones con el Gobierno nacional de J. D. Perón el permiso para la distribución de tierras y la incorporación de las familias Qom a un plan de desarrollo agrícola en la zona del paraje de Campo Medina.

9 Los distintos procesos de campesinización entre los pueblos indígenas del Chaco se desarrollaron en relación a las posibilidades de acceso a los recursos naturales, la participación en programas agrícolas -provenientes del Estado o de las Misiones eclesiásticas- y el acceso a determinadas políticas públicas en cada momento histórico.

10 Por ejemplo, los trabajadores de origen Guaraní, Nivaĉle, Moqoit y Qom en el tabaco y yerba mate en Misiones, caña de azúcar en Salta y Tucumán y en el algodón en Chaco y Formosa.

11 Para Valenzuela y Scavo (2009), la situación de crisis algodonera se desencadenó por los problemas de rendimiento y el endeudamiento de productores de escala pequeña y mediana (derivado de pagos pautados a cosecha futura) junto a la desregulación estatal en la comercialización. Mientras que un subgrupo más capitalizado se reconvirtió al nuevo modelo, otros debieron abandonar la actividad y poner en venta sus campos o subsistir apoyados por programas nacionales, provinciales y municipales proveedores de insumos.

12 Principalmente porque la misma era complementada con las remesas (enviadas a quienes no se encontraban en condiciones de trabajar -ancianos y niños-) y los escasos ahorros percibidos en las labores asalariadas, los cuales eran utilizados, por ejemplo, para la compra de herramientas de laboreo, vestimenta, alimentos extras, etc.

13 Recientemente, en el año 2017, la provincia de Chaco encabezó -junto con Salta- el ranking de provincias con mayores índices de desmonte en Argentina. Fuente: Informe "Monitoreo del Gran Chaco Americano". Asociación Guyra Paraguay. Recuperado de: https://goo.gl/vJ6p47

14 Los Qom relacionan el avance de las privatizaciones de tierra con la desarticulación de sus prácticas de caza y recolección a partir de las prohibiciones para ingresar al monte y los severos castigos que padecían al momento de hacerlo. Por ejemplo, aquellos que ingresaban a la Estancia y Cabaña "Don Panos", en búsqueda de leña, eran maniatados por la seguridad privada del lugar y llevados caminando hasta la comisaría más cercana, a unos $50 \mathrm{~km}$.

15 En el marco del reconocimiento de derechos específicos para pueblos indígenas que impulsó la Ley No 3258 -De las Comunidades Indígenas (http://endepa.org.ar/contenido/Ley-3258.doc)-, y la Reforma Constitucional de 1994, el gobierno provincial procedió a la adjudicación definitiva -bajo modalidad individual y comunitaria- de las parcelas indígenas reconocidas previamente y entregado a las familias bajo permisos de ocupación.

16 Entre los más importantes repertorios de protesta se encuentran las denominadas "Marchas del Impenetrable". Las mismas comenzaron en el año 2002 y estuvieron organizadas por diversos movimientos sociales y vinculados, principalmente, al Partido Comunista Revolucionario (PCR). Consistían en movilizaciones masivas de campesinos y pueblos originarios por las rutas provinciales con destino a la ciudad capital Resistencia, para visibilizar los reclamos y demandas. Durante estos 16 años, esta acción colectiva ha cobrado envergadura política y mediática, y se ha convertido en estratégica por parte de los movimientos sociales para efectivizar sus reclamos.

17 Para Perelmiter (2012), la peculiaridad de las burocracias asistenciales del Estado central argentino es que su funcionamiento institucional se ha desarrollado históricamente en ausencia de un poder infraestructural propio. En esta materia, el Estado ha apelado una y otra vez a "efectores" que mediatizaron su presencia territorial: la Iglesia y las organizaciones benéficas, los partidos políticos, los gobiernos subnacionales, las ONG y los movimientos sociales. Como consecuencia, esta intermediación volvió, por un lado, más relevante el poder despótico emanado de aquellos que ocupan posiciones de gobierno y, por el otro, más autónomo el poder de las múltiples organizaciones involucradas en la implementación de la asistencia.

18 El Plan "Manos a la Obra" fue anunciado por el Presidente de la Nación Néstor Kirchner (2003-2007) y ejecutado por el Ministerio de Desarrollo Social y la Secretaría de Políticas Sociales. Estuvo destinado a financiar más de 7000 proyectos productivos (entre los que se encontraban emprendimientos agrícolas y hortícolas, de panadería, fábricas de dulces, entre otros) en 7 regiones del país (500 municipios) con un presupuesto de 300 millones de pesos para el año 2003 y 655 millones, en 2004. El programa supuso la presentación previa de propuestas -vía ONG o municipios-, la adjudicación de herramientas, insumos y bienes de capital y el posterior seguimiento técnico por parte de agencias estatales. Entre los objetivos, se buscaba la capacitación de los beneficiarios y el trabajo cooperativo para generar políticas de carácter "no transitorio" (como lo eran por ese entonces, la asignación mensual del Plan Jefas y Jefes de Hogar Desocupados) y aumentar los ingresos familiares en los sectores de menos recursos. 
19 Nos referimos a las relaciones políticas que los indígenas mantenían con el movimiento de desocupados (Corriente Clasista y Combativa) de la ciudad de Resistencia.

20 Desde esta perspectiva, existe una diferencia entre la economía popular y la economía solidaria, pues la primera alude a las organizaciones populares de trabajo e ingreso, mientras que la segunda refiere a organizaciones económicas que apuntan a la sobrevivencia, proponen alternativas políticas y recuperan saberes de los sectores sociales para una transformación social. Este concepto nos permite recuperar la discusión del problema del poder y el Estado capitalista dentro de las prácticas económicas y solidarias. En efecto, no se plantea crear "otra” economía (alternativa) sino atender a la realidad social a partir del compromiso histórico de los sectores populares la búsqueda de condiciones de existencia que respondan a sus intereses marginados dentro de los procesos de colonialidad y desarrollo capitalista. Y también, esto nos permite considerar la realidad social como un entramado de relaciones de explotación, dominación y conflicto respecto a los ámbitos sociales, entre ellos el trabajo (Quijano, 2011; Marañón-Pimentel, 2012).

21 En la comercialización de la cosecha para la campaña algodonera 2003-2004, el ingreso total promedio de las familias indígenas ascendía a $\$ 800$. Si bien esto duplicó su ingreso anual, este total percibido contemplaba el trabajo de seis meses de producción. Vale aclarar, que para ese año el Instituto Nacional de Estadísticas y Censos (INDEC) estimaba que la línea de pobreza se encontraba en $\$ 720$ por mes. Fuente: Una Cosecha que renovó la esperanza (2004). Diario La Nación

22 Nos referimos a las fumigaciones aéreas con agrotóxicos realizadas por parte de la Estancia y Cabaña Don Panos (del grupo Corporación América perteneciente al empresario Eduardo Eurnekian) sobre el cultivo de soja aledaño a las viviendas de indígenas en el paraje de Campo Medina. Las mismas no sólo dañaron los cultivos, también la salud de la población se deterioró considerablemente. Esto repercutió en el ámbito político y mediático y, luego de sucesivas denuncias efectuadas por vecinos, técnicos de INTA e integrantes de la Red de Salud Popular Doctor Ramón Carrillo, se dictó en el año 2012 una medida cautelar a la Estancia Don Panos para restringir las fumigaciones a 600 metros del alambrado. Fuente: La vida fumigada (2015) Revista La Vaca.

23 En el Censo Nacional de Población, Hogares y Viviendas (2010), los datos estadísticos generales indicaron que sobre el total de la población indígena de Chaco (urbana y rural) el porcentaje de población no económicamente activa ascendía al 53,8 \%. Asimismo, En Pampa del Indio en el año 2014 trabajamos en un relevamiento socioproductivo a pedido de la FNC. Sobre un total de 130 familias relevadas, el 64,5\% vivía en condiciones habitacionales adversas (vivienda de adobe y hacinamiento), con graves dificultades sanitarias (escasez de recursos para mantener en condiciones los reservorios de agua). Del total de familias, sólo el 10,6 \% declaró tener ingreso por trabajo temporal extrapredial (“changas"), mientras que el recurso económico predominante de la población era el beneficio social de la Asignación Universal por Hijo (AUH). Fuente: FNC, 2014.

24 Respecto a la sequía, las precipitaciones anuales en Pampa del Indio llegaron a descender a 579 mm en el período 2010-2012 con una media histórica de $961 \mathrm{~mm}$ /anual. Fuente: Departamento de hidrología superficial, 2017.

25 En el año 2015 la planta a nivel nacional de trabajadores y trabajadoras del INTA se redujo en 850 personas. Asimismo, en los últimos años, su presupuesto de funcionamiento fue reducido drásticamente. Fuente: Argentina: INTA en crisis presupuestaria y con ajustes (29/03/19).Prensa de APINTA.

26 El Programa lo brinda la actual Secretaría de Desarrollo Social de la Nación e incentiva la formación de oficios, la ejecución de trabajos (limpieza, mejoramiento de espacios públicos, etc.) y la finalización de los niveles de estudio obligatorios en Argentina. Fuente: MDSN, 2019.

27 Las organizaciones participantes del semillero fueron: Federación Nacional Campesina (FNC), la Corriente Clasista y Combativa (CCC) y el Movimiento de Originarios en Lucha (MOEL).

28 Fuente: Exitosa cosecha: "Luchamos hace 15 años para no irnos del campo" (8/09/17). Diario Chaco día por día. Recuperado de: https://bit.ly/2KpIuFZ .

29 Para ilustrar estas afirmaciones, reproducimos un extracto de nuestras notas de campo: "Un primer aspecto que observamos al visitar a Lelia, en el paraje rural de Campo Medina fue su preparación para salir a recorrer la chacra: buscaba una botella con agua, se vestía con ropa que para cubrir brazos y piernas y se ponía calzado cerrado. La huerta comunitaria ubicada a unos 70 metros de la vivienda era sólo distinguible por un 'boyero' instalado de manera rudimentaria que cumplía la función de cerco (para la eventual intromisión de animales de los vecinos). Apenas lo cruzamos, Lelia me indicó que debía continuar su paso mientras ella abría camino con las manos entre la diversidad de plantas y arbustos. Debajo de ellas, me fue mostrando e identificando los plantines de batata, mandioca y papa, además de señalarme otras tantas aromáticas y de uso medicinal. La fisonomía del lugar estaba distante de las imágenes que tenía de una huerta; no había cercos marcados, ni fragmentación entre los cultivos. Incluso, parecía que las semillas se habían esparcido "al voleo", sin planificación. Todo era parte de un mismo paisaje de monte. Sobre el momento de cosecha, me contó que ellos "sacaban" para cocinar lo que iban a consumir en el día y solo las sandías las habían extraído de la planta para cuidarlas del sol. Además, era usual que los vecinos se acerquen a pedir, o también, llegaba 'gente de afuera' vía contacto del técnico de INTA”. Fuente: Notas de campo. Parcela de Leila López, Campo Medina, enero 2018. 